\title{
Article
}

\section{The social life of the novel idea: What did social psychologists ever do for us?}

Barrett, Jennifer Eve, Goulding, Jack Steven and Qualter, Pamela Available at http://clok.uclan.ac.uk/7653/

Barrett, Jennifer Eve ORCID: 0000-0002-6795-1615, Goulding, Jack Steven and Qualter, Pamela (2013) The social life of the novel idea: What did social psychologists ever do for us? Engineering, Construction and Architectural Management, 20 (3). pp. 250-266. ISSN 0969-9988

It is advisable to refer to the publisher's version if you intend to cite from the work. http://dx.doi.org/10.1108/09699981311323998

For more information about UCLan's research in this area go to http://www.uclan.ac.uk/researchgroups/ and search for < name of research Group>.

For information about Research generally at UCLan please go to http://www.uclan.ac.uk/research/

All outputs in CLoK are protected by Intellectual Property Rights law, including Copyright law. Copyright, IPR and Moral Rights for the works on this site are retained by the individual authors and/or other copyright owners. Terms and conditions for use of this material are defined in the policies page.

\section{CLoK}

Central Lancashire online Knowledge www.clok.uclan.ac.uk

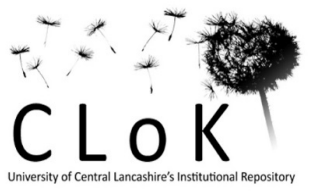




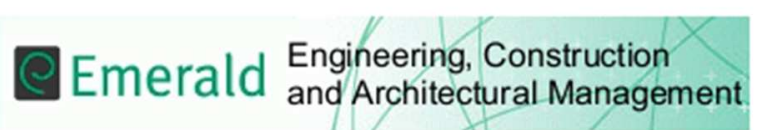

The Social Life of the Novel Idea: What did social psychologists ever do for us?

\begin{tabular}{|r|l|}
\hline Journal: & Engineering, Construction and Architectural Management \\
\hline Manuscript ID: & ECAM-Jun-2012-0067.R1 \\
\hline Manuscript Type: & Original Article \\
\hline Keywords: & Innovation, Design, Performance, Project teams, Group working \\
\hline Abstract: & \multicolumn{3}{c}{ SCHOLARONE } \\
& \multicolumn{3}{c}{ Manuscripts } \\
& \multicolumn{3}{c}{}
\end{tabular}




\section{Introduction}

This paper explores the social dynamics at work in the development of innovative designs within built environment design teams. It presents and summarises the existing body of literature in relation to innovative design in construction projects, and analyses literature in the field of social psychology which offers further expansion and consolidation of existing knowledge in the Architecture, Engineering and Construction (AEC) field. Key themes explicit within the literature relating to the study of behaviour within small groups are explored: their applicability to the AEC sector as areas for future research are discussed, and the creation of methods which may manipulate social interaction to enhance opportunities for the production of innovative design work in construction project teams.

\section{Theoretical background}

The design of buildings is a multi and interdisciplinary design process. Whilst it requires a complex array of related skills and knowledge, simply asking architects and engineers to work alongside each other has often been considered insufficient. It is, therefore, inappropriate to assume that such teams know how to collaborate toward a favourable or optimal solution, and simply putting creative people in the same room, does not necessarily yield creative results (Leonard and Swap, 1999). Moreover, it is advocated that the AEC disciplines must collaborate as a highly interdependent group.

In the latter part of the twentieth century, the catalogue of construction reports (Figure 1) observed that, within practice, such collaboration was fraught with challenges; the success of the constructed outcomes was considered to be highly dependent on the effective management of the social processes within the team environment (Murray \& Langford, 2003). Despite this, many have noted that research into AEC collaborative performance improvements have centred upon operational improvements or technological advance, with scant attention paid to behavioural approaches (Dainty et al., 2006; Shelbourn et al., 2007; Kululanga, 2009; Gorse, 2011; Love et al., 2011).

Whilst behavioural aspects have been explored widely in design and creative thinking, research in this field, historically, tends to be weighted towards exploration of design activity as an individual and cognitive process (MacKinnon, 1965; Goldschmidt, 1995; Goldschmidt and Badke-Schaub, 2010; Pour Rahminian and Ibrahim, 2011). More recently, design has been explored theoretically as a social and collaborative process too, notably in Pryke's $(2004 ; 2005)$ mapping of social networks in construction projects and in Bucciarelli's (1994) description of design as a social process of interaction and negotiation. Further, it is considered as aspects of Cross's design thinking (2011) and in the outcomes of the recent Design Thinking Research Symposia (DTRS). Of particular interest within the DTRS7 proceedings (McDonnell and Lloyd, 2009) is Matthews's statement that which asserts that:

"The very identification of designers' normative orientations (e.g. to the local relevance of talk) is one important step towards the creation of formats of interaction that might be able to 'tamper' with social order, in similarly mild ways, so as to be more conducive to design objectives."

(Matthews, 2009) 
This paper seeks to develop an understanding of how this 'social order,' at work in built environment design teams, influences their ability to produce innovative design ideas. It searches within the field of social psychology to see what it can offer in assistance towards the creation of formats for design, which may be more conducive and supportive of innovative performance.

\section{Methodology}

This paper is the first to bring together the existing theory relating to the social aspects of innovative design performance and to examine the literature in the AEC and social psychology fields in order to connect social interaction and innovative design performance and creative thinking in small groups. Literature is presented in the form of a comparative analysis between the two disciplines: First, aspects of social processes of innovation which are already present within the AEC field are established and concepts/ideas in social psychology that are likely to be important in understanding group processes within the field of AEC are examined; Second, elements of social psychology which may be used to expand, consolidate and develop our understanding of built environment design teams, and identify gaps in AEC specific knowledge are identified. Ultimately, then, key areas for future research are presented.

A thematic approach has been adopted in presentation of the literature. Three main themes from social psychology that are important for understanding small group social processes within AEC are considered: (1) social climate, (2) risk attitudes and (3) motivation and reward. These three themes are important concepts within social psychology and help explain creative decision-making (social) processes in small groups. In the current paper, these ideas are applied to small groups within the AEC field. Social psychology theory also identifies a fourth heading, which relates to issues of leadership. Our decision to consider only three main themes with the omission of leadership is that the study of leadership deals with personality characteristics and attitudes and not the direct social processes within small groups (Davis et al., 1976). Whilst there are many reasons to believe that team leaders can be important in creating a shared and task-adaptive understanding (van Ginkel and van Knippenberg, 2012), discussion of this large area of empirical study is beyond the scope of the current paper. The focus, instead, is on the social processing of information within small groups within AEC.

\section{Innovation and ideas in the design team}

The nature of innovation specific to the construction industry is described by Slaughter (1998) who distils a set of models of innovation which respond to sector activities. She identifies five types of innovation:

1. Incremental innovations

2. Radical innovations

3. Modular innovations

4. Architectural innovations

5. System innovations

These typologies are arranged on a scale of change as a way to enhance companies' awareness of innovation opportunities and the likely impacts of innovation on resources and outcomes (Slaughter, 1998). The applicability of this is relevant in a sectoral and organisational capacity, but requires 
further discussion in relation to the conception, presentation and adoption of the innovative idea within the multidisciplinary design environment. Whilst there is an increasing body of work which considers social influence as a driver or limiter of innovative design (Agars et al., 2008; Runco, 2008, Wong et al., 2009), this still to be transferred and applied extensively within the AEC research field (Kululunga, 2009).

The Construction Research and Innovation Strategy Panel (CRISP, 1997) offer a valuable definition of innovation as "the successful exploitation of new ideas where ideas are new to a particular enterprise, and are more than just technology related - new ideas can relate to process, market or management."

This definition offers a separation of the 'new idea,' which becomes an 'innovation' when implemented successfully. This is further explained by Amabile et al., (1996), an influential writer in the field of social psychology and creativity. Amabile describes creativity as "the production of useful and novel ideas" and innovation as "the successful implementation of ideas." In light of this definition, when discussing the social aspects of innovation in the design team, this paper will focus upon the extent to whether social interaction can hinder or facilitate the presentation of the 'novel idea' within the collaborative design space, to use the vocabulary of the co-evolution design model (Maher et al., 1996; Dorst and Cross, 2001). This is supported by existing observational research which notes the generation of novel ideas being limited, or design direction being steered, as a symptom of implied and normative social interaction (Matthews, 2009; Barrett, 2010).

\section{The social life of the novel idea}

Research in the field of social psychology has expanded and gathered impact since the 1930s when Elton Mayo's Hawthorne studies linked the industrial performance of engineers to social issues within groups (Mayo, 1949). Social psychology as a field for scholarly exploration may be traced back to Aristotle and Plato who acknowledge the existence of group-level processes (Aristotle, 384322B.C.; Plato, c.380B.C.), but it is the development and acceptance of a scientific approach to group research in the early $20^{\text {th }}$ century that enabled it to gather momentum and deliver insights into how the behaviour of one person might impact on that of another. More relevant here, is the application of these studies to work-based teams, which led to a large body of work linking social behaviours to productivity and performance. Such is the legacy of scholars at the Research Center for Group Dynamics at the Massachusetts Institute of Technology (Forsyth and Burnette, 2005).

Whilst studies in social psychology may not specifically consider their application to design process, it is assumed that the human condition remains constant and the social behaviours which influence creative performance also do so within the AEC sector. A number of studies, notably the recent analyses of the DTRS7 dataset (McDonnell \& Lloyd, 2009), seek to analyse communication (drawn, written, gestural or verbal) in the design process as a tangible representation of the mutual expectations and shared understandings of the design team (Cross, 1996; Dong, 2007; Emmitt and Gorse, 2007; Matthews, 2009; Visser, 2009; Oak, 2011). These studies can provide us with some valuable knowledge about what happens during collaborative design and how it may be analysed, providing us with the foundations to carry out further research which will address the behavioural themes presented in the social psychology literature and apply them to the resultant design outcomes - in this case, innovation in building design, performance and process. These include 
studies of 'design moves' as in protocol analysis (Cross, 1996) or studies in communication in construction teams which draw their methodology directly from the social psychology field, through Bales's (1950) Interaction Process Analysis (Emitt and Gorse, 2007). Deeper observation also acknowledges the relevance of informal talk and interaction between design team participants to establish role allocation and transfer of normative values which facilitate the ability of design team participants to gain a comprehensive understanding of the shared and 'imagined' building and their ability to move and explore its innovative possibilities (Goldschmidt \& Eshel, 2009; Lloyd, 2009; Luck, 2009)

\section{The social climate}

If the cliché, 'thinking outside the box' describes a route to innovation by way of independent thought, then the social psychology literature presents to us a problem. Landmark experiments of the 1950s (Asch, 1955; Deutsch and Gerard, 1955; French, 1956) demonstrated the effects of social pressures on judgement and decision making. Findings showed that an individual will change his opinion when faced with a unanimous majority, even when he is correct. Hence, our ability to 'think outside the box' and foster independent thought and offer clear judgement is compromised by the cultural norms (Kelman, 1961). This influences our future behaviour via our own senses of reward and failure, in that conformity to group norms promote feelings of self-esteem and self-approval whilst non-conformity causes feelings of anxiety and guilt (Deutsch and Gerard, 1955).

Further studies identify the effects of 'group standards' which demonstrate a convergence of judgements to a cultural norm, developing towards group 'cohesiveness.' The degree of group cohesiveness is then a factor in influencing members to stay in the group or to conform to its normative values in their individual decision-making or behaviour (Sherif, 1936; Schacter, 1951). In recent years, the AEC industry has embraced the creation of more cohesive teams through initiatives such as partnering contracts and partnerships with clients and throughout the supply chain. These less ephemeral alliances can take advantage of long term familiarity by reaping the social benefits of continuous, collaborative learning and an environment of psychological safety as long as it promotes a team climate which is conducive to innovative performance. Indeed the positive effects of long term relationships with cohesiveness as a key characteristic underpins Latham's (Latham, 1994) proposals for industry reform through development of the 'integrated team.' Morton et al., (2006) observed that product development teams who are more familiar each other are indeed more effective. This is developed in a design environment by Badke-Schaub et al. (2009) who acknowledge the relevance of social interaction in the development of a shared team mental model of the design. They note how this 'sharedness' requires time to develop and how the shared mental model influences team performance depends upon group co-ordination of roles, cohesiveness and leadership.

Whilst cohesiveness may generally be considered conducive to performance, creative problem solving may also be hampered by 'groupthink,' the social phenomenon which occurs within cohesive groups with symptoms which include ignoring alternatives and hampering rational thought (Janis, 1982). Indeed, Egbu et al. (1998) note the impact of entrenched cultural norms as a barrier to construction innovation and this is observed to be especially true for contracting organisations (Kululanga, 2009). 
There is a tendency for individuals to seek social consensus or validation from the group and each team will have their own implicit values and validation of what constitutes their task. This concurs with the DTRS7 analysis (Badke-Schaub et al., 2009)which describes cohesiveness as three communication acts - informal talk (non-task related); appreciation (explicit statements of liking) and confirmation (a shorter form of appreciation) - which allow the team to develop and shape their shared mental model of the building they are designing. The relevance of informal talk is also underlined as a way to allow interpretative flexibility and hence shaping and delimiting the shared mental model, but also as a way of building cohesiveness through the appeal to informal, social relationships (Bucciarelli, 1994; Glock, 2009; Cross, 2011).

The transfer and shaping of normative values in design teams have also been observed by Le Dantec and Yi-Luen Do (2009) in their study of the mechanics of transfer and sharing of ethical values through spoken interaction during design revision. However, embedded within the cohesiveness and 'sharedness' of the team mental model of the design problem and solution, is a shared creation of its limits (Breuer et al., 2012). If opportunities for innovation are omitted from these shared values or receive low priority, then a group norm will have developed in which innovation does not form part of the accepted focus or task effort. This is known as 'social tuning' where group norms and values - which may either foster creativity/originality or convergence/conformity - evolve from intra-group validation and reinforcement (Adarves-Yorno et al., 2007; Bechtoldt et al., 2010). This is observed in a study of team climate in Australian architecture and engineering design teams where organisational culture and leadership were found to have a key role to play in fostering innovation in their ability induce a team climate that was supportive of and receptive to innovative performance (Panuwatwanich et al., 2008).

The group norms may also influence the perception of what is to be deemed 'creative' (AdarvvesYorno et al., 2007). Furthermore, individuals may fear contradicting the norm which may inhibit presentation of potentially innovative solutions (Walton, 2003). A psychologically safe environment created by a more inclusive, socially cohesive group dynamic is more likely to promote creativity and this is supported by the findings of Morton et al. (2006) who observed that effectiveness in product design teams strongly correlates with the presence of trust, respect and loyalty. The positive mood from good social cohesion supports increased cognitive flexibility and hence, increased likelihood that creative or novel solutions will be found (Paulus and Dzindolet, 2008; Wong et al., 2009).

Tensions held between consensus and conflict may characterise the life cycle of group decisionmaking but in-group conflict can actually be caused by an individual or sub-group who present a creative or novel idea. The effect can be the strengthening of whole group attachments, thus making the creative people feel separate or part of an 'outgroup.' This is due to the creative proposition being counter group norms of creativity acceptance (Walton, 2003) and may be applied to the differing cognitive models of design between architects and engineers who navigate the solution search space differently resulting in different models of the 'imagined building' resulting in the characteristic interdisciplinary tensions experienced in built environment design teams (BadkeSchaub, 2009). This is given further clarity by 'social comparison theory' (Festinger, 1954) that suggests that individuals tend to move in the direction of a social comparison referent. Hence, whilst there is a convergence of values to a median referent, there will be an upward convergence in relation to ability (Paulus and Dzindolet, 2008). This would help to explain the differences in group norms in relation to the valuing of creativity and innovation as well as their abilities to deliver it. 
Team climate is a distinct area of research in organisational psychology literature which explores the shared perceptions of organisational norms and values. Team climate may be explored via a number of perceptional facets, with one common facet of team climate study pertaining to innovation capacity (Anderson and West, 1998). This research area is developing to consider the relationship between team climate and team performance and task outcomes (Gonzalez-Roma et al., 2009), necessarily moving beyond organisational-level research to that of work groups (Anderson and West, 1998). Epistemological wisdom suggests that when team climate is strongly supportive of innovation, performance in this domain can be enhanced with even small differences having significant effects (Hurley, 1995; Gonzalez-Roma et al, 2009). In addition, there is some research which suggests that a positive team climate creates positive mood states which in turn encourages greater cognitive flexibility and hence, enhanced creative performance. Interestingly though, when a negative climate induces negative mood states which prompt an active response (e.g. anger, fear rather than sadness or depression), creative performance is enhanced through sheer persistence (Nijstad et al., 2010). These aspects of work group climate for innovation are summarised in West's four factor theory which identifies predictors of innovativeness - vision, participative safety, task orientation and support for innovation (Anderson and West, 1998)

\section{Risk attitudes}

Decision making in built environment design and evaluation of innovative solutions frequently comprises a discussion of the relevant risks and trade off of those risks. Established within social psychology theory, project participants are more likely to take risks if they are part of a cohesive team which promotes psychological safety and adopts a shared value of risk acceptance. However, in an historically litigious industry (Latham, 1994), it would be expected that innovation struggles to exist within the risk averse and adversarial culture that this generates.

Where innovation thrives, it is attributed to the existence of a team which exhibits a willingness to share risk and, clear, potential rewards for subsequent innovation in the construction product or process (Russell et al., 2006). As a result, Egbu et al. (1998) observe in four AEC organisations that innovation is more likely to occur when a risk tolerant climate is achieved. This is observed in teams which perform more effectively when a 'no blame culture' is consciously employed (Baiden et al, 2006) and exemplified in a number of architectural projects which are widely considered to be 'innovative.' For example, the success of the Downland Gridshell (Edward Cullinan Architects/Buro Happold) is attributed to the technical innovations applied to create the complex timber structure. This is documented as attributable to the risk tolerant, non-adversarial and positive team climate facilitated by the client and maintained in project team interaction (Harris et al., 2003)

The field of social psychology offers further, significant and more detailed discussion that considers the valuation and acceptance of risk in collaborative decision-making. In a study of the effects of group interaction on risk and caution in decision making, a significant Master's thesis study by Stoner in 1961 (Stoner, 1968; Cartwright, 1971; Pruitt, 1971) noted that greater risk taking occurs during social interaction than during individual evaluation. Wallach et al (1962) later posits that this is due to a spreading of responsibility for risks across the group and the fact that individuals with a previous propensity for taking risks are more likely to become dominant within that group. Interestingly, Wallach also notes that group members are likely to maintain the higher level of risk 


\section{Motivation and reward}

The work of Amabile (Amabile, 1983; Amabile et al., 1988; Amabile et al., 1996) explored the social environment as a driver of creative performance, with particular focus on the role of motivation. The wide internalisation of this work within the fields of business, government and education and its focus on creative performance suggests that it may also offer insight into how design team members' motivation may influence their innovative performance. The AEC sector considers the relevance of motivational theory and in Oyedele's (2010) study of architects and engineers in design firms, he identified four critical success factors for increased motivation. These were:

1. Favourable project working conditions

(e.g. the psycho-social and organisational working environment)

2. Organisational support

(e.g. commitment to employees' career development; appropriate evaluation and feedback mechanisms)

3. Design process efficacy

(e.g. harmonious working relationship within the design team; good communication)

4. Efforts recognition

(e.g. appropriate reward, whether monetary or non-monetary)

The fourth is also supported by Egbu et al., (1998) who notes that innovative solutions are not fostered where there is a lack of motivational reward. If innovative performance is desired, the 
foresight to apply these critical success factors to the procurement and selection methods of design teams may be one option to ensure successful results.

Amabile (1983) also noted the dynamic relationship between intrinsic and extrinsic motivators. Whilst intrinsic motivators such as personal autonomy, intellectual challenge and satisfaction in achievement enhance creativity, this can also be undermined by extrinsic pressures. Such pressures may include rigid organisational control or in-group strife (Amabile et al., 1996). Alternatively, creativity may be fostered by a conducive social environment which further enhances intrinsic motivation within the individual. This may be achieved by encouraging collaborative idea flows and a shared commitment to creative thinking, for example (Amabile et al., 1996).

The impact of motivation on innovative design performance is highlighted in their survey and interviews with built environment engineering designers at Arup. Here, Salter and Gann (2003) observe that those involved in non-routine design processes rely heavily on face-to-face conversations with other designers for solving problems and developing new, innovative ideas. When considering motivation as a key driver of innovation in design, intrinsic factors such as a sense of professionalism are cited, but also the extrinsic, organisational and project-based factors which allow opportunities for innovation are also considered significant. Other extrinsic motivators are found to include the simple act of creating a new structure, satisfying client needs and the social reward of working in a team. However, as predicted by Amabile (1996), certain extrinsic barriers are also found to limit innovative thinking in the design process. These barriers include insufficient time; insufficient budgets and conflicting workloads. Interestingly, this research also concludes that it is the opportunities for face-to-face social interaction that are more significant in creating opportunities for innovation than the knowledge management tools which support information access and arguably it is the latter that have received more attention in recent research and practice.

With this in mind, design managers who wish to enhance innovative performance must therefore endeavour to establish a collaborative, face-to-face culture which fosters the intrinsic motivation to be creative and minimises the extrinsic barriers to idea generation and flow (Amabile et al., 1996, Nijstad et al., 2010). These principles must continue to be managed throughout design and delivery as Amabile's work is further echoed in construction literature by the suggestion that the failure of construction companies to adopt and diffuse the innovations presented may act as a demotivator to employees, becoming a barrier to innovative activity in the future (Steele and Murray, 2004).

Returning to the field of social psychology, an additional aspect of motivation explores the notion of reward as an influential factor in facilitating innovation. The Theory of Co-operation and Competition (Deutsch, 1949) sets a foundation for exploring differences in the behaviour and performative potential of groups when individual motivation is either prosocial or proself (Pruitt and Rubin, 1986; Beersma and DeDreu, 2005; Bechtoldt et al., 2010). In prosocial behaviour, individuals are working towards the collective success of the group, whilst in proself behaviour; the individual is seeking to 'win' at the expense of group consensus or harmony. It is to be expected that in collaborative teams, collaborative behaviours such as information sharing; communication of goals and priorities as well as giving and making concessions will enhance performance. Indeed, more effective problem solving behaviour has been observed in pro-socially motivated groups, with egoistic motivation driving out problem solving, inhibiting motivation to collect full information and overconfidence, all damaging to innovation capacity (DeDreu et al., 2000). 
Counter-intuitively, the presence of proself behaviour have been found to enhance collective results in the long run (Beersma and DeDreu, 2005). An individual's attempts to create further value in a competitive environment are considered to be more conducive to divergent thought processes those associated with brainstorming and idea generation. Hence, the group overall is more prolific in producing original ideas. However, when integrative behaviours are required such as during decision making and project execution, it is the convergent through processes that are needed as the usefulness of ideas is the goal, rather than number. Hence, it is asserted that a prosocial environment is required (Beersma and DeDreu, 2005) for delivery. Such a collaborative reward structure may have a negative effect on speed of project delivery and overall creative output (Beersma et al., 2003; Johnson et al., 2006). This has clear implications for the design process which requires both divergent and convergent thought processes, corresponding simplistically with the concept and implementation phases.

The nature of the reward structure as an aspect of motivation has clear applicability to issues of procurement in the construction industry and their influence on the innovative capacities of construction teams. The influence of the choice of procurement route on group performance has been investigated in the AEC field in a series of studies which analyse the effects of a variety of reward packages on team performance. However, it is noted that performance incentives are not usually an important feature of procurement routes in relation to the role of design consultants, except in Prime Contracting where consultants are incentivised through a shared savings scheme (Pryke, 2005). In a study of a range of procurement routes, Baiden et al (2006) observe that the highest levels of integration are observed in the team procured through a Design and Build route and thus whilst innovation is not a specific measure in this study, their performance overall is acknowledged as higher than those procured by other routes. In another study, it was noted that the nature of the risk/reward package and the way that it is distributed amongst the design team did influence group behaviour through its perceived levels of equity and fairness, thus prompting varying levels of willingness to explore alternative design options or expend effort into modifications that would improve the design or add value (Love et al., 2011). It is important to note the impact of the client's role here too, as perceptions of equity and fairness may derive from a design team understanding that they were selected fairly and on the basis of competence, past performance or capacity to add value, rather than under traditional price-focussed criteria (Rose and Manley, 2010). This highlights the significance of the way in which the design team is procured as a driver of innovative performance, rather than as a by-product facilitated by in-project management (Russell, 2006).

In summary, the significance of the pre-commission activities of the client is evident in his role in determining procurement method; selection criteria and payment/penalty structures. The industry has already taken steps to improve in this area by seeking to develop more cohesive teams in the form of new procurement mechanisms such as Partnering arrangements or Public Private Partnerships, which take advantage of longer term relationships to promote better collaboration towards value return (Aouad et al., 2010). Similarly, during the design process, the effects of clientarchitect communication relating to cost limitation is significant in presenting a barrier or facilitator of creative performance (Wallace, 1987). 


\section{Discussion}

By analysing the social psychology literature in parallel with the extant research from the AEC field, it is apparent that there has been a groundswell in the AEC literature since the latter years of the twentieth century relating to social interaction and its influence on the innovative performance of AEC design.

However, it is evident from the analysis of literature from both fields, that the field of social psychology can offer a significant theoretical resource, with significant areas that remain underexplored, yet have clear relevance, for the AEC sector. Using the thematic approach gained from the social psychology literature, three areas emerge as having special and specific significance for built environment design teams: the social climate, attitudes to risk, and motivation/reward structure.

Figure 3 shows that, from the relevant theoretical framework within the social psychology field, the AEC sector has supplanted some key elements in its exploration of the innovative capacity of built environment design teams. There is clear evidence of discussion relating to effects of social climate, for example, and this focusses on the effects of cohesiveness and this is linked to the focus upon the definition and implementation of the 'integrated team' in response to government direction. This cohesiveness is further explored through effects of conflict and 'groupthink' and the need for psychological safety through trust, respect and loyalty on creating the appropriate environment for creative thinking and shared innovative response to the design problem.

Theories of motivation and reward are also well-represented within the AEC field. These are explored particularly in relation to the intrinsic motivators; extrinsic barriers and reward structures which may limit or hinder the novel idea within the design environment and frequently in relation to procurement and selection methods.

Furthermore, a more quantitative analysis, expressed chronologically and thematically in Figure 1 shows that this research is a relatively recent phenomenon and, whilst these aspects of social psychology are present on our understanding of how AEC groups work towards innovation, there is still some significant work to do to embed these principles firmly within our understanding of the social process of design.

There are also further aspects of social climate and motivation and reward that still require consideration in terms of our own discipline. The influence of team climate, how teams support innovative thinking, and the influence of cultural norms still require consideration. Similarly, the effects of social tuning and social comparison also remain unstudied in relation to AEC teams. Theories of motivation and reward also require further development, particularly in relation to the factors that motivate teams to innovate as well as an application of the theory of co-operation and competition within the design process and how this affects design outcomes.

Most notably, however, is the limited presence of research relating to the effects of shared risk attitudes in design teams. Whilst the construction industry has embraced risk as a critical element of management in design and construction, it would appear that the behavioural facet of this term has been neglected. It would also appear that the ability of design teams to take risks as a fundamental part of creative thinking is also limited within the AEC field. In particular, our understanding of design decision making would benefit from further exploration into how teams might share risk 
responsibility; the nature of the 'risky shift' in design teams as well as the application of the theories of risk adjustment and acceptance in design interaction.

\section{Conclusion}

This paper has reviewed, connected and synthesised the relevant and significant work in the field of social psychology and AEC to derive a theoretical framework which can be used to direct further research towards development of the behavioural facet of design management. Whilst, some aspects of social processes are well represented in the AEC literature, the social life of the novel idea is not yet fully understood in the management of built environment design teams. The comparative analysis of the social psychology literature and that represented within the AEC has been invaluable in yielding some key areas which would benefit from further research. Development of these behavioural facets is imperative if we are to balance the operational improvements and technological advances already achieved in relation to building innovation. Development of these behavioural facets is also critical if we are to strengthen our understanding of how teams may be better designed and managed to capitalise on individual creative currency, and work towards a collaborative environment that allows innovative thinking to thrive. 


\section{REFERENCES}

Adarves-Yorno, I., Postmes, T. and Haslam, S.A. (2007) Creative Innovation or Crazy Irrelevance? The contribution of group norms and social identity to creative behaviour in Journal of Experimental Social Psychology, Vol.43, pp410-416

Agars, M.D., Kaufman, J.C. and Locke, T.R. (2008) Social Influence and Creativity in Organisations: A multi-level lens for theory, research and practice in Mumford, M.D., Hunter, S.T. and Avers-Bedell, K.E. (eds) Multi-level Issues in Creativity and Innovation, Elsevier, Oxford, pp3-61

Amabile, T. (1983) The Social Psychology of Creativity, Springer-Verlag

Amabile, T.M. (1988) A Model of Creativity and Innovation in Organizations in Research in Organizational Behaviour, Vol.10, pp123-167

Amabile, T.M., Conti, R., Coon, H., Lazenby, J. and Herron, M. (1996) Assessing The Work Environment For Creativity in Academy of Management Journal, Vol.39(5), pp1154-1184

Anderson, N.R. and West, M.A. (1998) Measuring Climate for Work Group Innovation: Development and validation of the team climate inventory in Journal of Organisational Behaviour, Vol.19, pp235-258

Aouad, G., Ozorhon, B. and Abbott, C. (2010) Facilitating Innovation in Construction: Directions and implications for research and policy in Construction Innovation, Vol. 10(4) pp374-394

Aristotle (?date) Politics in Berseth, J. (ed) (2000) Aristotle Politics, Dover Publications, Ontario

Asch, S.E. (1955) Opinions and Social Pressure in Scientific American, Vol.193(5), pp31-35

Badke-Schaub, P., Lauche, K., Neumann, A. and Ahmed, S. (2009) Task, Team, Process: The development of shared representations in an engineering design team in McDonnell, J. and Lloyd, P. (eds.) About:Designing; Analysing Design Meetings, Taylor \& Francis

Baiden, B.K., Price, A.D.F. \& Dainty, A.R.J. (2006) The Extent of Team Integration Within Construction Projects in International Journal of Project Management, Vol.24(1)

Bales, R.F. (1950) Interaction Process Analysis, Addison-Wesley, Cambridge, MA

Barrett, J. (2010) Evolving the Idea: Designing teams for detailed design in Proceedings of the $9^{\text {th }}$ International Detailed Design in Architecture Conference, $4^{\text {th }} \& 5^{\text {th }}$ November, 2010, University of Central Lancashire, Preston, UK

Bateson, N. (1966) Familiarisation, Group Discussion, And Risk Taking in Journal of Experimental Social Psychology, Vol.2

Bechtoldt, M.N., De Dreu, C.K.W., Nijstad, B.A. and Choi, H. (2010) Motivated Information Processing, Social Tuning and Group Creativity in Journal of Personality and Social Psychology, Vol.99(4), pp622-637

Beersma, B., Hollenbeck, J.R., Humphrey, S.E., Moon, H., Conlon, D.E. and Ilgen, D.R. (2003) Cooperation, Competition and Team Performance: Toward a contingency approach in Academy of Management Journal, Vol.46(5), pp572-590

Beersma, B. and De Dreu, C.K.W. (2005) Conflict's Consequences: Effects of social motives on postnegotiation creative and convergent group functioning and performance in Journal of Personality and Social Psychology, Vol.89(3), pp358-374 
Breuer, O., Caglio, A., Gottlieb, F., Groskovs, S., Hiltunen, A., Sanint, M.N. \& Schewe, B. (2012) The Facets of Design Thinking in Rodgers, P. (2012) Articulating Design Thinking, Libri Publishing

Brown, R. (1965) Social Psychology, Free Press of Glencoe, New York

Bucciarelli, L.L. (1994) Designing Engineers, MIT Press, Cambridge

Burnstein, E. (1969) An Analysis of Group Decisions Involving Risk ("The Risky Shift") in Human Relations Vol.22 pp381-395

Butler, R.J. (1981) Innovations in Organizations: Appropriateness of Perspectives From Small Group Studies For Strategy Formulation in Human Relations Vol.3

Cartwright, Dorwin (1971) Risk Taking By Individuals And Groups: An assessment of research employing choice dilemmas in Journal of Personality and Social Psychology Vol.20:3 pp.361-378

Construction Research and Innovation Strategic Panel (CRISP): Motivation Group (1997) Creating A Climate Of Innovation, Report to UK Construction Industry Board (CIB).

Cross, N. and Clayburn Cross, A. (1996) Observations of Teamwork and Social Processes in Design in Design Studies, Vol.16, pp143-170

Cross, N. (2011) Design Thinking: Understanding how designers think and work, Berg Publishers

Dainty, A., Moore, D., and Murray, M. (2006) Communication in Construction: Theory and practice, Taylor and Francis, London.

Davis, J.H., Laughlin, P.R., \& Komorita, S.S. (1976). The social psychology of small groups. Annual Review of Psychology, 27, 501-541.

De Dreu, C.K.W., Weingart, L.R. and Kwon, S. (2000) Influence of Social Motives on Integrative Negotiation: A meta-analytic review and test of two theories in Journal of Personality and Social Psychology, Vol.78(5), pp889905

Deutsch, M. (1949) A Theory of Co-operation and Competition in Human Relations, Vol.2, pp129-152

Deutsch, M. and Gerard, H.B. (1955) A Study of Normative and Informational Social Influences Upon Individual Judgement in Journal of Abnormal and Social Psychology, Vol.51(3) pp629-636

Dong, A. (2007) The Enactment of Design Through Language in Design Studies, Vol.28(1), pp5-21

Dorst., K. \& Cross, N. (2001) Creativity In The Design Process: Co-evolution of problem-solution in Design Studies, Vol.22(5)

Egbu, C.O., Henry, J., Kaye, G.R., Quintas, P., Schumacher, T.R. and Young, B.A. (1998) Managing Organisational Innovations In Construction in Hughes, W. (ed) $14^{\text {th }}$ Annual ARCOM Conference, 9-11 September, 1998, University of Reading, Association of Researchers in Construction Management, Vol.2, pp605-614

Emmitt, S. and Gorse, C. (2007) Communication in Construction Teams, Taylor and Francis, Abingdon

Festinger, L. (1954) A Theory of Social Comparison Processes in Human Relations, Vol. 7(2), pp117-140

Forsyth, D.R. and Burnett, J.L. (2005) The History of Group Research in Wheelan, S. (ed) The Handbook of Group Research and Practice, Sage, London 
French, J.R.P. (1956) A Formal Theory of Social Power in Psychological Review, Vol.63(3), pp181-194

Glock, F. (2009) Aspects of Language Use in Design Conversation in McDonnell, J. and Lloyd, P. (2009)

About:Designing: Analysing Design Meetings, Taylor \& Francis

Goldschmidt, G. (1995) The Designer As A Team of One in Design Studies, Vol.16(2), pp189-209

Goldschmidt, G. and Eshel, D. (2009) Behind the Scenes of the Design Theatre: Actors, roles and the dynamics of communication in McDonnell, J. \& Lloyd, P. (eds.) About:Designing: Analysing Design Meetings, Taylor Francis

Goldschmidt, G. and Badke-Schaub, P. (2010) The Design-Psychology Indispensable Research Partnership in Proceedings of the $8^{\text {th }}$ Design Thinking Research Symposium (DTRS8), 19-20 October, Sydney, pp199-209, DAB Documents, Australia

Gonzalez-Roma, V., Fortes-Ferreira, L. and Peiro, J.M. (2009) Team Climate, Climate Strength and Team Performance: A Longtitudinal Study in Journal of Occupational and Organizational Psychology, Vol.82, pp511536

Gorse, C.A. (2009) Researching Interpersonal Communication in AEC Projects in Emmitt, S., Prins, M. and den Otter, A. (eds) Architectural Management: International Research and Practice, Wiley-Blackwell, Chichester, pp55-71

Harris, R., Romer, J., Kelly, O. and Johnson, S. (2003) Design and Construction of the Downland Gridshell, in Building Research and Information, Vol.31(6)

Hurley, R.F. (1995) Group Culture and Its Effect on Innovative Productivity in Journal of Engineering and Technology Management, Vol.12, pp57-75

Janis, I.L. (1982) Groupthink: Psychological studies of policy decisions and fiascos, Houghton Mifflin, Boston Johnson, M.D., Hollenbeck, J.R., Humphrey, S.E., Ilgen, D.R., Jundt, D. and Meyer, C.J. (2006) Cutthroat Cooperation: Asymmetrical adaptation to changes in team reward structures in Academy of Management Journal, Vol.49(1), pp103-119

Kelman, H.C. (1961) Processes of Opinion Change in Public Opinion Quarterly, Vol.25, pp57-78

Kululanga, G.K. (2009) Construction Process Improvement Through Cognitive Power Under Team Generative Learning in Engineering, Construction and Architectural Management, Vol.16, No.4, pp307-324

Latham, M. (1994) Constructing the Team, HMSO, London

LeDantec, C. and Yi-Luen Do, E. (2009) The Mechanisms of Value Transfer in Design Meetings in McDonnell, J. and Lloyd, P. (eds.) About:Design: Analysing design meetings, Taylor \& Francis

Leonard, D.A. and Swap, W. C. (1999) When Sparks Fly: Igniting creativity in groups, Harvard Business School Press.

Levinger, G. and Schneider, D.J. (1969) Test of the 'risk is a value' hypothesis in Journal of Personality and Social Psychology Vol.11 pp165-170

Lloyd, P. (2009) Ethical Imagination and Design in McDonnell, J. and Lloyd, P. (eds.) About:Designing:

Analysing Design Meetings, Taylor \& Francis 
Love, P., Edwards, D. and Wood, E. (2011) Loosening The Gordian Knot: The role of emotional intelligence in construction in Engineering, Construction and Architectural Management, Vol.18, No.1, pp50-65

Luck, R. (2009) 'Does This Compromise Your Design?' Socially producing a design concept in talk-in-interaction in McDonnell, J. and Lloyd, P. (eds.) About:Designing: Analysing Design Meetings, Taylor \& Francis

MacKinnon, D.W. (1965) Personality and The Realization of Creative Potential in American Psychologist, Vol. 20(4), pp273-281

Maher, M.L., Poon, J., Boulanger, S. (1996) Formalising Design Exploration as Co-Evolution: A combined gene approach in Gero, J.S. and Sudweeks, F. (eds.) Advances in Formal Design Methods for CAD, Chapman \& Hall

Matthews, B. (2009) Intersections Of Brainstorming Rules and Social Order in McDonnell, J. and Lloyd, P. (eds.) About:Designing; Analysing design meetings, Taylor \& Francis

Mayo, E. (1949) The Social Problems of an Industrial Civilization, Routledge and Kegan Paul, London McDonnell, J. and Lloyd, P. (eds.) (2009) About:Designing: Analysing design meetings, Taylor and Francis Morton, S.C., Brookes, N.J., Dainty, A.R.J., Backhouse, C.J. and Burns, N.D. (2006) The Role of Social Relationships in Improving Product Development Decision Making in Proceedings of the Institution of Mechanical Engineers, Part B, Journal of Engineering Manufacture, Vol.220(6), pp1017-1024

Murray, M. and Langford, D. (eds.) (2003) Construction Reports, Blackwell Science, Oxford

Nijstad, B.A., De Dreu, C.K.M., Rietzschel, E.F. and Baas, M. (2010) The Dual Pathway To Creativity Model: Creative ideation as a function of flexibility and persistence in European Review of Social Psychology, Vol.21, pp34-77

Nordhøy, F. (1962) Group interaction in decision-making under risk. Unpublished Master's thesis, School of Industrial Management, Massachusetts Institute of Technology.

Oak, A. (2010) What Can Talk Tell Us About Design? Analyzing conversation to understand practice in Design Studies, Vol. 32(3), pp211-234

Oyedele, L.O. (2010) Sustaining Architects' and Engineers' Motivation In Design Firms: An investigation of critical success factors in Engineering, Construction and Architectural Management, Vol.17(2), pp180-196

Panuwatwanich, K., Stewart, R.A. and Mohamed, S. (2008) The Role of Climate for Innovation in Enhancing Business Performance: The case of design firms in Engineering, Construction and Architectural Management, Vol.15(5), pp407-422

Paulus, P.B. and Dzindolet, M. (2008) Social Influence, Creativity and Innovation in Social Influence, Vol.3 (4), pp228-247

Plato (c.380B.C.) Republic in Reeve, C.D.C. (trans.) (2004) Plato Republic, Hackett, Indiana

Pour Rahimian, F. and Ibrahim, R. (2011) Impacts of VR 3D Sketching on Novice Designers' Spatial Cognition In Collaborative Conceptual Architectural Design in Design Studies, Vol.32(3), pp255-291

Pruitt, Dean, G. (1971) Choice Shifts In Group Discussion: An introductory review in Journal of Personality and Social Psychology Vol.20:3 pp339-360

Pruitt, D.G. and Rubin, J.Z. (1986) Social Conflict: Escalation, stalemate and settlement, Random House, New York 
Pruitt, D.G. and Teger, A.I. (1969) The Risky Shift In Group Betting in Journal of Experimental Social Psychology Vol.5 pp115-126

Pryke, S.D. (2004) Analysing Construction Project Coalitions: Exploring the application of social network analysis in Construction, Management and Economics, Vol.22(8)

Pryke, S.D. (2005) Towards a Social Network Theory of Project Governance in Construction, Management and Economics, Vol.23(9)

Rose, T. and Manley, K. (2010) Client Recommendations for Financial Incentives on Construction Projects in Engineering, Construction and Architectural Management, Vol.17(3), pp252-267

Runco, M.A. (2008) Creativity Research Should Be A Social Science in Mumford, M.D., Hunter, S.T. and AversBedell, K.E. (eds) Multi-level Issues in Creativity and Innovation, Elsevier, Oxford, pp75-94

Russell, A.D., Tawiah, P. and De Zoysa, S. (2006) Project Innovation - A Function of Procurement Mode in Canadian Journal of Civil Engineering, Vol.33(12)

Salter, A. and Gann, D. (2003) Sources of Ideas For Innovation in Engineering Design in Research Policy, Vol.32(8)

Schacter, S. (1951) Deviation, Rejection and Communication in Journal of Abnormal and Social Psychology, Vol. 46(2), pp190-207

Shelbourn, M., Bouchlaghem, N.M., Anumba, C. and Carillo, P. (2007) Planning and Implementation of Effective Collaboration in Construction Projects in Construction Innovation, Vol.7, No.4, pp357-377

Sherif, M. (1936) The Psychology of Social Norms, Harper Collins, New York

Slaughter, E. Sarah (1998) Models of Construction Innovation in Journal of Construction Engineering and Management, Vol. 124 (3)

Steele, J. and Murray, M. (2004) Creating, Supporting and Sustaining a Culture of Innovation in Engineering, Construction and Architectural Management, Vol. 11(5), pp316-322

Stoner, J.A.F. (1968) Risky And Cautious Shifts In Group Decisions: The influence of widely held values in Journal of Experimental Social Psychology Vol.4 pp.442-459

van Ginkel, W.P. \& van Knippenberg, D. (2012). Group leadership and shared task representations in decision making groups. The Leadership Quarterly, 23, 94-106.

Visser, W. (2009) The Function of Gesture In An Architectural Design Meeting in McDonnell, J. \& Lloyd, P. (eds.) About:Designing: Analysing Design Meetings, Taylor and Francis

Wallace, W.A. (1987) Capital Costs Versus Costs-In-Use: A content analysis of design team member communication patterns in Construction Management and Economics, Vol.5, pp73-92

Wallach, M.A., Kogan, N. and Bem, D.J. (1962) Group Influence on Individual Risk-Taking in Journal of Abnormal and Social Psychology, Vol.65(2), pp75-86

Walton, A.P. (2003) The Impact of Interpersonal Factors on Creativity in International Journal of Entrepreneurial Behaviour and Research, Vol. 9(4), pp146-162 
Wong, E.M., Kray, L.J., Galinsky, A.D and Markman, K.D. (2009) Stimulating creativity in groups through mental stimulation in Mannix, E.A., Neale, M.A. and Goncalo, J.A. (eds) Creativity In Groups, Emerald, Bingley, pp111134 
Figure 2: The Risky Shift Phenomenon From: Butler, R.J. (1981)

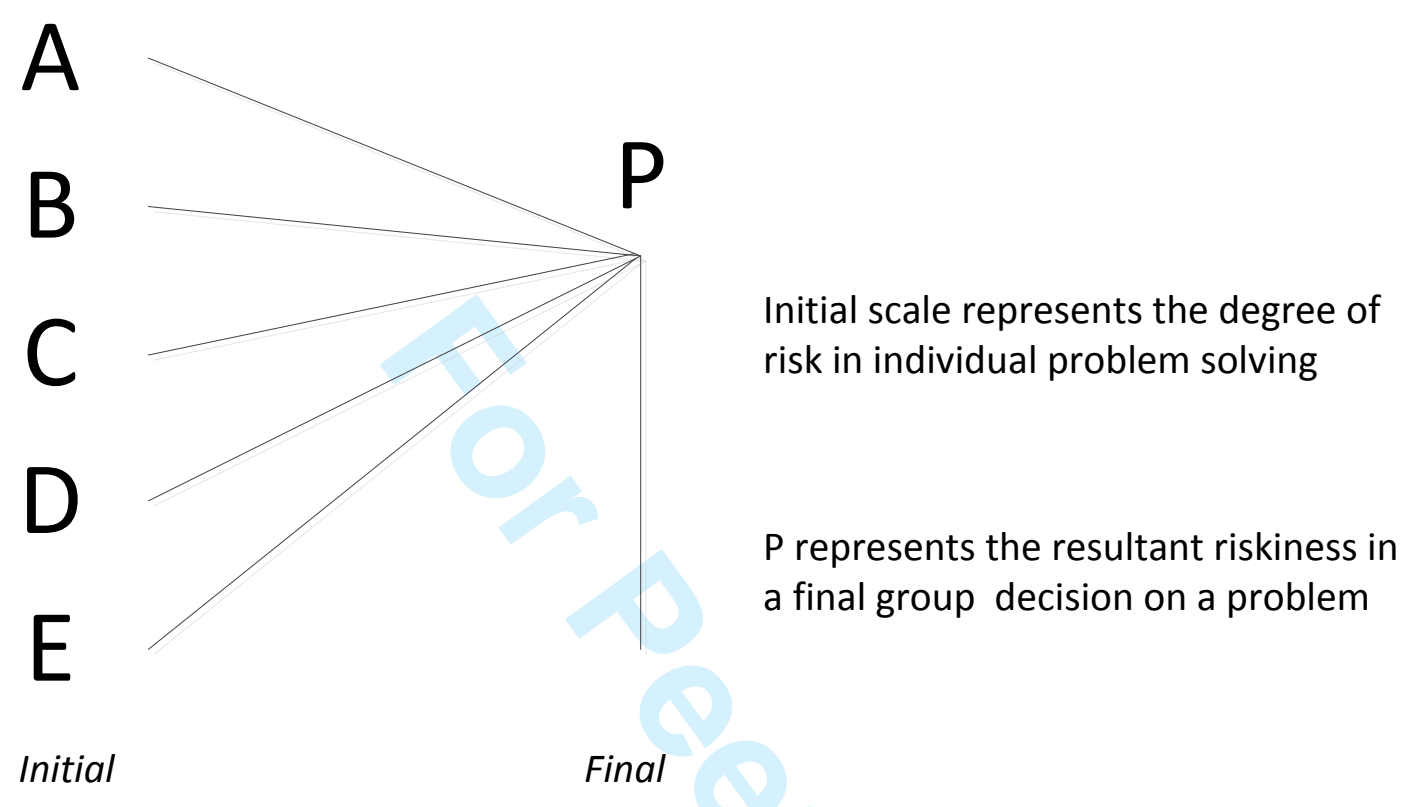




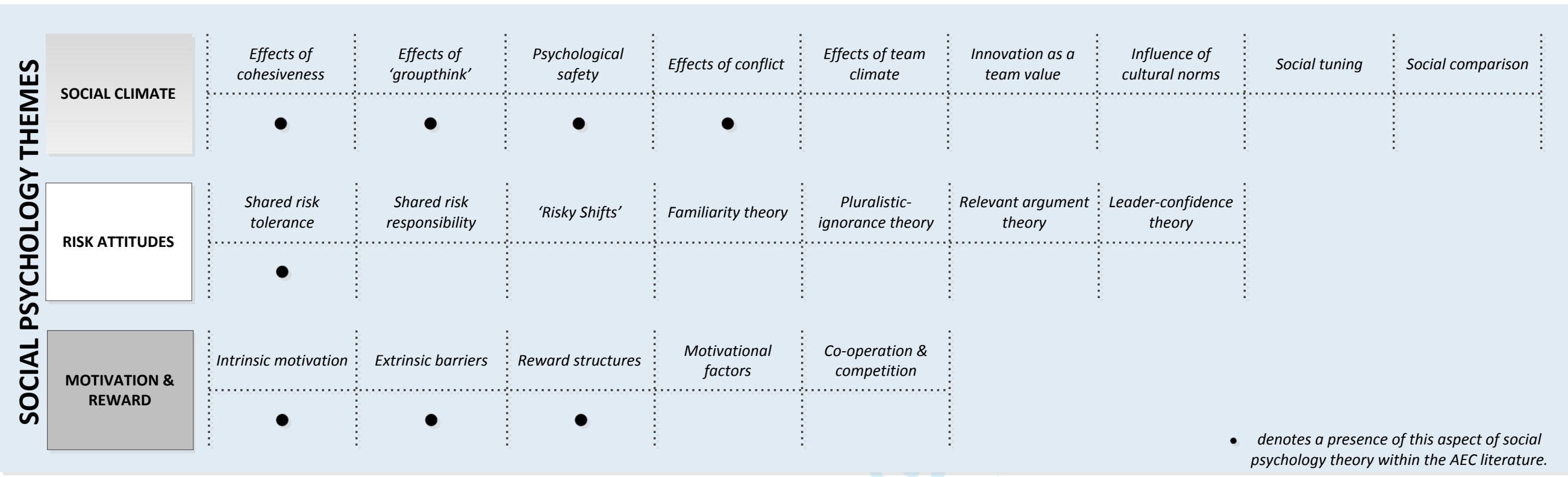

Figure 3: Theoretical framework within the social psychology field relating to innovative performance in teams and its representation in the AEC field. 